\title{
Safety Review of Severe Accident Senario for Wet Spent Fuel Storage Facility
}

\section{사용후핵연료 습식저장 시설의 중대사고 안전성 검토}

\author{
Tae-Myung Shin1) \\ Chungju National University, 50 Daehak-ro, Chungju, Chungbuk \\ 신태명1) \\ 충주대학교, 충북 충주시 대학로 50
}

(Received November 23, 2011 / Revised December 20, 2011 / Approved December 21, 2011)

\begin{abstract}
When the Fukushima nuclear power plant accident occurred in March of 2011, a hydrogen explosion in the reactor building at the 4th unit of Fukushima plants led to a big surprise because the full core of the unit 4 reactor had been moved and stored underwater at the spent nuclear fuel storage pool for periodic maintenance. It was because the possible criticality in the fuel storage pool by coolant loss may yield more severe situation than the similar accident happened inside the reactor vessel. Fortunately, it was assured to be evitable to an anxious situation by a look of water filled in the storage pool later. In the paper, the safety state of the spent fuel storage pool and rack structures of the domestic nuclear plants would be roughly reviewed and compared with the Fukushima plant case by engineering viewpoint of potential severe accidents.
\end{abstract}

Key words : Severe Accident, Fuel Building, Spent Fuel Storage Rack, Seismic Safety

요 약

지난 2011년 3월의 후쿠시마 원전 사고시 원자로 건물에서의 연쇄적인 수소폭발이 발생하였을 때 관계 자들은 제 1 원전 4 호기의 폭발에 더욱 놀랐었는데 이는 그 당시 4호기는 정기보수를 위하여 원자로내 모 든 핵연료를 저장조에 보관중이었기 때문이다. 저장조내 냉각수 유실로 노심에서 옮겨진 핵연료가 공기 중에 노출되어 수소가 발생하고 임계가 도달하였다면 더욱 심각할 수도 있기 때문이었는데 다행히 추후 에 양호한 냉각수 상태가 확인되어 우려할 상황을 피할 수 있었다. 본 논문에서는 후쿠시마 원전 사고를 계기로 국내 원자력 발전소내 핵연료 임시 저장시설의 안전성과 관련하여 중대사고 관점에서 검토해 보 고자 한다.

중심단어 : 중대사고, 핵연료건물, 사용후핵연료저장대, 내진안전성

1) Corresponding Author. E-mail : tmshin@cjnu.ac.kr 


\section{I. 서 론}

우리를 충격과 공포로 떨게 하던 2011년 3월의 일본 후쿠 시마 원전사고도 벌써 발생한지 수개월이 지나면서 서서히 뇌리에서 잊혀져가고 있다. 그 동안 다양한 방법을 통하여 국 내원전에 대한 종합적인 안전성 재평가를 실시하고 시설 보 완을 추가로 실시하여 적어도 일본의 경우와 유사한 쓰나미 가 국내원전에 발생하여도 안전성에 문제가 없도록 조치하고 있다고 한다. 후쿠시마 원전사고는, 최근까지 원자력발전량 으로 세계 5위를 기록한데 이어 요르단과 연구용 원자로 수 출계약, $\mathrm{UAE}$ 와 원전 4 기 수출계약도 성사시켜 원자력 르네 상스를 외치며 승승장구하던 국내외 원자력 업계에 있어서 그야말로 찬물을 끼엊는 사건이었다. 그동안 영광, 고리, 월 성, 울진 등 4 개 부지의 21 기 원전에서 국내 전력 생산의 약 3 분의 1을 차지하여 왔고 2016년까지 7기, 2030년까지 11기의 원전 추가 도입 계획 등 원자력 발전 위주로 활기차게 진행해 온 중장기 전력수급 계획에도 큰 영향을 주어 재검토 중이다. 사실 에너지 정책은 궁극적으론 태양광 - 풍력 · 수력 등으로 가야 좋겠지만 이러한 신재생 에너지는 최근까지 약 $3 \%$ 의 에 너지를 충당하고 있을 뿐이고, 2024년이 돼야 9\% 정도로 늘 어날 것으로 예측된다. 따라서 오존층 파괴와 지구 온난화를 방지하기 위해 1997년 맺어진 교토협약에 의해 우리도 조만 간 온실가스 감축의무를 피할 수 없고 자원빈국으로서 적절 한 대안이 없다보니 당분간 값비싼 화석에너지의 수입 증가 보다는 풍부한 인적자원과 기술력을 바탕으로 하는 원전의 비중을 늘려갈 수밖에 없다는 입장이 설득력을 얻고 있는 편 이다. 요점은 일본 사고를 계기로 주요 시설들의 안전성을 재 검토하여 안전신뢰도를 향상시키고 투명한 정책을 시행해야 할 것이다. 이러한 의미에서 본 논문에서는 후쿠시마 사고로 인하여 원자로 격납용기와 함께 중요성이 크게 부각된 사용 후핵연료 저장시설의 중대사고 가능성을 되짚어 보고 국내 원전의 안전성 문제를 재검토해 보고자 한다.

\section{II. 후쿠시마 원전 사고시 사용후핵연료 저장시설의 안전성 검토}

사용후핵연료 저장조는 원자로 격납용기 내의 핵연료를 정기적으로 교체하거나 임시 이송하여 수중에서 냉각 및 보 관하려는 목적으로 설계되는 수영장 같은 구조의 수조이다. 후쿠시마 원전은 비등경수형(BWR) 원자로인데 설계개념상 원자로 건물내 원자로 상부에 설치를 하고 있다. 사고 당시 자동냉각기능의 상실로 인하여 운전중이던 원자로 건물의 연
쇄 수소폭발이 발생하여 원자로 노심의 핵연료 용융과 같은 중대사고에 관심이 모아져 있을 때에, 운전정지 중이던 후쿠 시마 제 1 원전 4 호기의 건물에서까지 수소폭발이 일어나자 전 문가들은 순간 크게 당황하게 되었다. 재해당시 정기점검으 로 원자로내 핵연료를 전부 방출한 4호기의 경우 격납건물 상부에 위치한 사용후핵연료 저장조에서 발생(추후, 수소가 이웃 원자로 3호기 건물에서 유입되었다고 공식 보고됨)한 수소로 인해 폭발이 발생했다는 점에서 사용후핵연료 저장조 의 손상 가능성도 부각되었다. 나중에 내부에 설치된 폐쇄회 로 TV를 확인한 결과, 수조의 냉각수는 다행히도 일정량 이 상의 수위를 유지하고 있는 것으로 나타났지만, 만일 원자로 에서 방출된 지 얼마 안되는 사용후핵연료가 냉각수 일부 상 실로 공기 중에 노출되었다면 수소발생은 물론 과열에 의해 피복재가 녹아 제어가 곤란한 상태에서 그 속에 갇혀 있던 독 성 방사성기체를 외부로 방출시킬 수 있기 때문에 격납용기 내의 사고에 비해 더 심각할 수도 있었다는 것이 전문가들의 주장이다. 사고시 관심대상 사용후핵연료 저장시설의 상태를 간단히 요약하면 다음과 같다.

(1) 원자로 건물 인근의 공용 사용후핵연료 습식저장수조 : 지 진 및 해일 피해는 없으며 보관중인 사용후핵연료는 냉각기 간이 몇 년 지나 붕괴열이 상당히 줄어든 상태라 수소폭발의 위험은 없다고 보고됨.

(2) 4호기 사용후핵연료 저장수조 : 지진에 의한 직접피해는 없다고 보며 일본당국은 사고초기에는 4 호기 저장수조의 핵 분열 가능성이 “zero가 아니다”라고 발표하였으나 추후 Fig. 1 에서 보듯이 감시카메라에 의한 사진과 저장수조 육안 점검 결과 핵연료 손상은 없는 것으로 확인됨.(1)

이에 따라 핵연료 손상으로 인한 재임계 가능성은 희박하

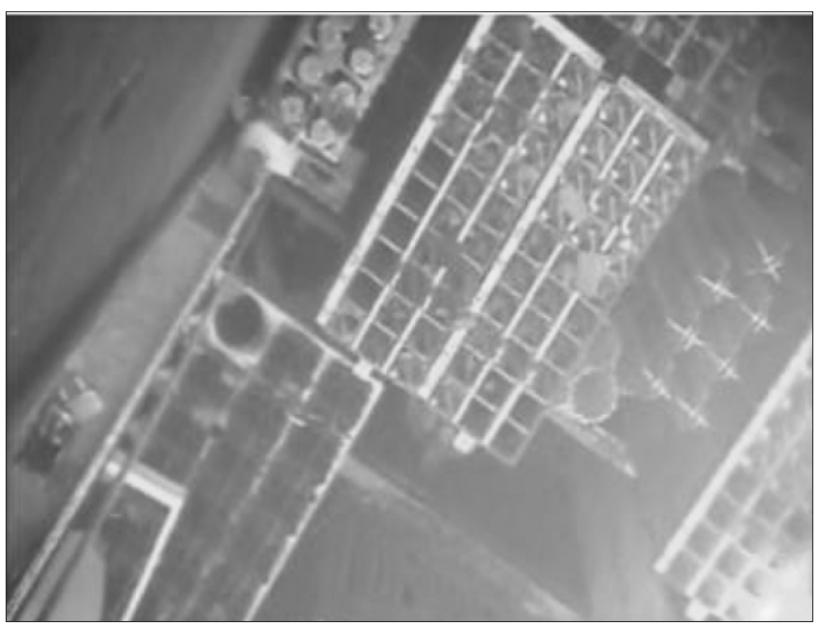

Fig. 1. View of Spent Fuel Storage Pool after Hydrogen Explosion at Fukushima Plant Unit 4(1). 
다고 결론지었다. 다만, 추정할 수 있는 냉각수 상실 시나리 오는 지진 발생 시 구조물의 흔들림으로 냉각수가 출렁거리 며 일부 누설되거나, 전원 상실에 따른 팽창식 밀봉장치의 기 능 저하로 인한 냉각수 누설, 지진에 따른 저장수조 벽체의 직접 손상으로 인한 냉각수 누설, 건물 내부 수소폭발의 충격 으로 발생한 손상에 따른 냉각수 누설 등으로 볼 수 있었다.

그리고 4 호기 저장수조를 조밀 저장대로 교체하여서 분열 속도가 상승하는 효과가 있을 수 있으나, 집합체의 기하학적 구조만 유지된다면 임계가 일어날 수 없는 것으로 분석하였 으며 재임계가 발생하더라도 지속 시간이 매우 짧기 때문에 시설 내부의 방사선준위는 일시적으로 높아지겠지만 시설 외 부로의 영향은 크지 않을 것으로 판단하였다. 그런데 이 사고 로 인하여 그 동안 노심 안전에만 치우첬던 고정 관념을 탈피 하여 어떠한 시나리오에 의해서든 사용후핵연료 저장수조의 냉각수가 상실되어 사용후핵연료가 고온에 도달할 수 있음을 깨닫게 되었으며, 저장수조 냉각기능 상실 등의 사고 대책을 사전에 마련할 필요에 공감하게 되었다. 따라서 이러한 사고 에 대비한 비상 냉각수공급 계통과 소방차 활용 등 다양한 냉 각기능 확보 방안 마련이 필요하며 저장수조의 다양한 사고 시나리오를 개발하고, 시나리오에 따른 사용후핵연료 거동을 파악하여 대비책을 마련하여야 하겠다.

\section{III. 국내 사용후핵연료 저장시설의 안전성}

\section{가. 국내 저장시설의 설계 특성}

국내에는 현재 고리, 영광, 울진, 월성에 위치한 17 기의 경수로형과 4 기의 중수로형 원전의 경우 수중에 사용후핵연 료를 보관하는 습식 저장시설이 원자로건물과 이웃한 핵연 료 건물에각각 설치되어 있다. 사용후핵연료 저장수조는 사 용후핵연료를 수중에서 취급 및 저장하는 시설로서 초기 경 수로형 원전의 경우 원자로의 재장전 또는 보수기간 동안 노심의 약 $1 / 3$ 및 전노심의 핵연료를 임시로 저장할 수 있 고, 노심으로부터 방출 직후의 고온 반응성을 지닌 사용후 핵연료를 중간저장시설로 이송하기 전 충분히 냉각시킬 수 있도록 약 3 5년분의 저장용량을 가지도록 설계되었다. 최 근 사용후핵연료의 중간저장과 재처리 등에 관한 정책결정 이 장기간 지연되면서 기존의 저장용량을 우선적으로 늘리 기 위해 고밀도 저장대를 적용하거나 소내 건식중간저장 시 설을 추가로 건설하여 임시저장하고 있다.

사용후핵연료 저장조와 내부에 설치되는 저장대는 공히 내진설계를 하고 있는데 저장조는 가로세로 약 20 30m, 높이 약 $12 \mathrm{~m}$ 의 수조로서 그 내부에 냉각수를 가득 채우고
수중 바닥에 사용후핵연료 저장대 구조물을 빽빽하게 여러 개 설치하여 냉각을 유지하도록 하고 있다. 참고로 경수로 형 원전의 저장대 모듈은 핵연료 사이의 최소거리를 물리적 으로 유지하기 위하여 Fig. 2 에 제시한 바와 같이 핵연료 크 기보다 조금 큰 사각기둥 형상의 스텐레스강 쎌을 가로세로 약 10 여개씩 벌집모양으로 용접하여 제작하며 각 쎌 내부로 폭 $20 \mathrm{~cm}$, 길이 $4.5 \mathrm{~m}$ 정도의 핵연료를 수중에서 수직으로 삽입하여 저장하고 있다.

Fig. 3에 나타낸 것처럼 중수로형 원전의 경우에는 직경 $20 \mathrm{~cm}$ 길이 $60 \mathrm{~cm}$ 정도 크기의 핵연료를 저장용 트레이라 불 리는 프레임형 지지구조물 내에 수평으로 24 다발씩 나열한 다음 각 트레이를 약 16 18 층 높이까지 수중에 적재하여 저장하는 방식을 택하고 있다.

Fig.4에서 보듯이 경수로형과 중수로형 핵연료는 형상과

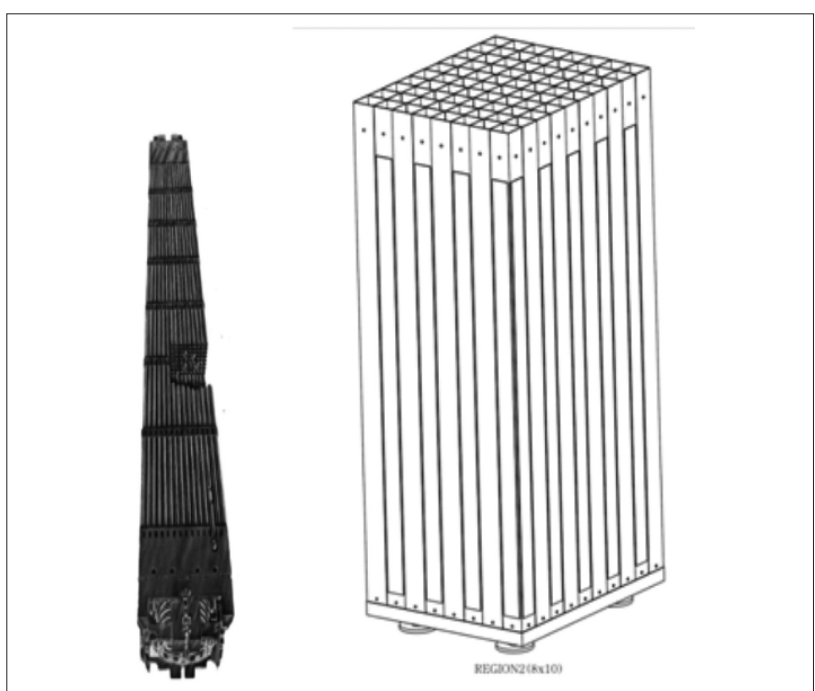

Fig. 2. PWR Fuel Ass'y and Storage Rack Module.

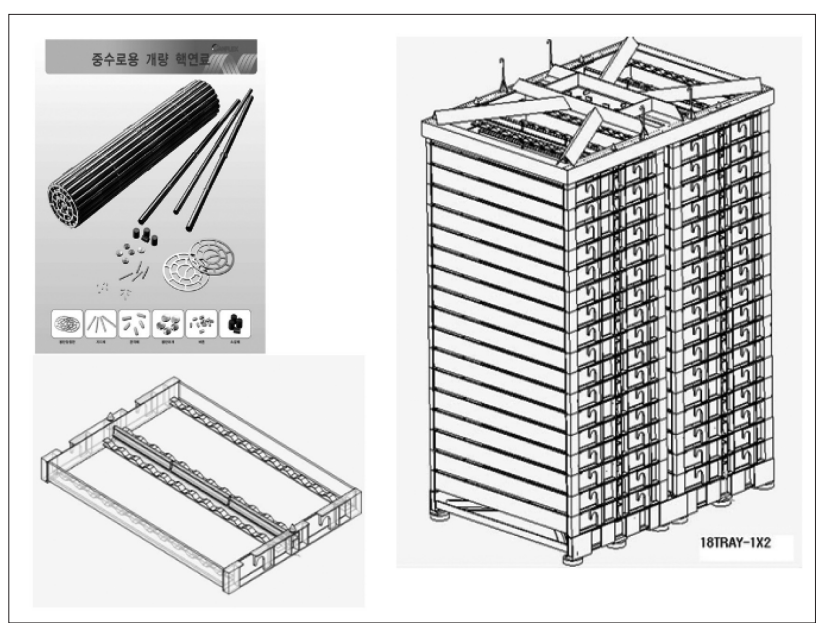

Fig. 3. PHWR Fuel Ass'y, Tray, and piled Stack. 
크기가 다르지만 핵연료 건물내 수중에 저장하는 임시저장 개념과 저장조 자체 형상은 유사하다.(2)

\section{나. 후쿠시마 원전과의 중대사고 안전성 비교}

여기서 중대사고란 원전의 설계기준사고(DBA, 원전의 설 계시부터 안전한 대처가 가능하도록 고려된 사고)를 초과해 원자로 노심 또는 핵연료의 손상을 야기하는 사고를 의미하 며 대표적인 사례로는 최근의 일본 후쿠시마 원전사고를 포 함하여 1979년 미국 스리마일(TMI) 사고와 1986년 옛 소련 (현 우크라이나)의 체르노빌 사고가 있다.

후쿠시마 사고를 토대로 국내 원전의 사용후핵연료 저장 시설의 중대사고 가능성 및 시설안전과 관련하여 비교한다 면 아래 Fig. 5 에서 볼 수 있듯이 비등경수로(BWR)형인 후 쿠시마 원전은 저장수조가 원자로건물의 상단에 위치하지 만 이와 달리 경수로(PWR)형 또는 중수로(PHWR)형인 국 내설계는 사용후핵연료 저장조가 원자로건물과 이웃한 핵 연료 건물 내에 위치하고 있다. 따라서 사용후핵연료 저장 시설로의 접근성 관점에서 살펴본다면 사고시 냉각수 공급

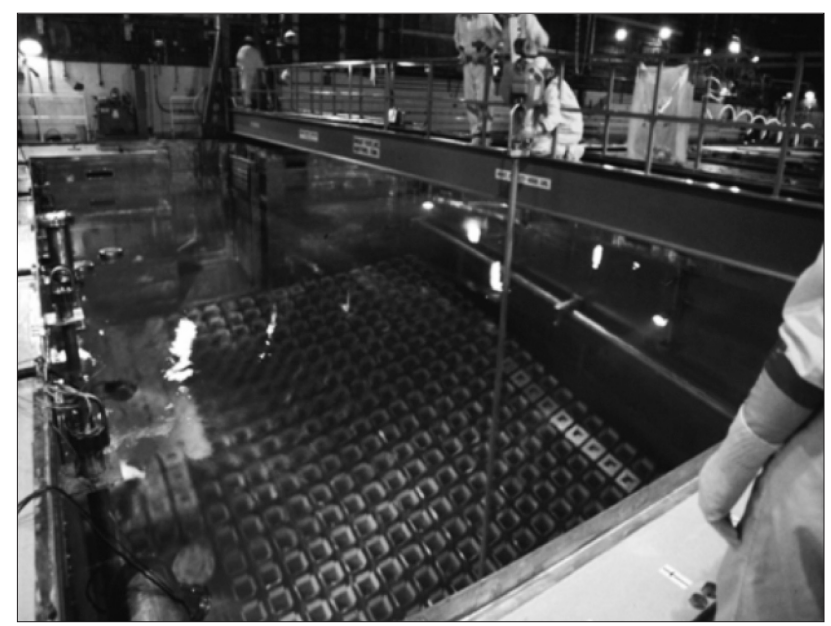

Fig. 4. PWR Spent Fuel Storage Pool.

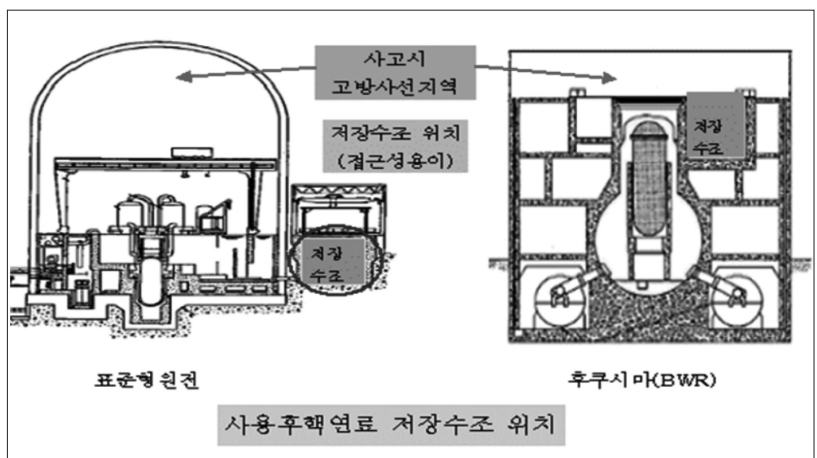

Fig. 5. Comparison of Accessibility to Storage(2).
또는 보충이 필요할 경우 고방사선 지역을 통과하지 않아도 되는 국내 원전이 후쿠시마 원전에 비해 상대적으로 월등히 유리하다.

\section{다. 국내 사용후핵연료 저장시설의 중대사고 시나리오 및 분석}

중대사고 관점에서 가정할 수 있는 사용후핵연료 습식저 장 시설의 안전성을 위해할 수 있는 심각한 사고는 결과적 으로 사용후핵연료의 냉각수 유출 또는 공급부족에 의한 냉 각기능의 상실 사고인데 공학적으로 볼 때 일부를 제외하면 발생 가능성이 극히 낮아 대부분 고려하고 있지 않다. 이하 다소 무리한 가정이라 하더라도 후쿠시마 사고를 계기로 설 계기준 내에 있거나 이를 초과하는 몇 가지 사고 시나리오 를 가정하여 검토한다. 참고로 9.11과 유사한 테러 등에 의 한 항공기 충돌사고, 설계지진 보다 강한 지진에 의한 저장 조, 라이너, 또는 저장대 손상, 핵연료 취급사고, 쓰나미에 의한 전원 상실사고, 고밀도 저장대 교체작업 중의 사고 등 이 대상이다.

\section{(1) 항공기 충돌사고}

9.11 사태 이후 미국뿐만 아니라 원전 운영국들 대부분이 규제기관을 중심으로 항공기 충돌에 대한 대비책을 검토해 오고 있으며 적어도 중대사고에 의한 안전 문제가 없도록 예방할 수 있는 조치나 대안 등이 이미 주요시설에 반영되 고 있거나 조만간 기준에 반영될 것으로 예상된다. 현재까 지 건설된 핵연료건물은 항공기 충돌에 대비한 설계가 충분 히 마련되어 있지는 않지만 먼저 원전시설 부근으로의 항로 의 규제가 선행되고 혹시 이를 통과하여 낮은 확률로라도 핵연료 건물에 정확히 충돌한다 하더라도 폭파에 의해 격납 건물과 연결되어 있는 핵연료 건물 지붕과 외벽을 완전히 파손시키기는 불가능하다고 볼 수 있다. 또한 건물 지붕이 나 외벽이 상당부분 손상된다 하더라도 이차적으로 건물 내 부의 작업층 높이에 $12 \mathrm{~m}$ 깊이로 건설된 저장조를 추가로 파 손시키기에는 충분치 않을 것으로 판단된다. 또한, 저장조 일부가 크랙이 갈 정도로 손상이 있다 하더라도 내벽전체에 설치된 금속 라이너 부분에 의해 일정기간 누수를 방지할 수 있을 것이다. 라이너 구조물이 손상된다면 신속히 냉각 수 보충을 위하여 다양한 비상시스템이 가동되어야 할 것이 다. 혹시 내부 화재가 발생하는 경우에도 저장조의 냉각수 유출이 일어나지 않는다면 발전소 화재방호 시스템의 지원 으로 냉각문제는 정상화하는데 큰 어려움이 없을 것이다. 또한, 폭발시 작업층에서의 충격이 있더라도 $7 \mathrm{~m}$ 깊이의 수 중에 보관중인 사용후핵연료 저장대에 직접 큰 하중 영향을 
주기가 어렵고 낙하물 일부에 의해 저장대 상부가 변형될 수는 있으나 이는 냉각을 유지하면서 시간을 두고 적절한 후속조치를 취한다면 우려하는 중대사고는 충분히 피할 수 있을 것으로 판단된다. 그러나, 폭파의 여파가 워낙 커 저장 조 손상으로 빠른 누수가 진행된다면 대량 방사능 누출 등 의 문제를 야기할 수 있으므로 이를 예방하기 위한 핵연료 건물 지붕 및 외벽 보강 등의 대책이 필요할 것이다.

\section{(2) 지진에 의한 저장조 또는 라이너 손상}

과거에 건설된 국내 원전은 영주기가속도 $0.2 \mathrm{~g}$ 에 맞춰서 설계되어 있으며, 최근에 수출형 표준 원전은 기준을 높여 서 $0.3 \mathrm{~g}$ 로 설계되어 있는데 이는 리히터 규모로 볼 때 약 6.5 7.0 정도의 수준과 유사한 지진으로 보고 있다. 원전에 대한 설계지진의 결정은 국가의 최소기준뿐만 아니라 해당 지역의 지반 특성, 역사적 기록 등을 고려하여 설정되며 선 진국들의 원전에 대한 내진설계 방법들과 대부분 대등소이 하다. 다만, 설계기준 지진 이상의 지진이 올 경우에는 어떻 게 될 것인가를 만일 예측해 본다면 이는 실제 발생한 지진 의 크기, 건설된 구조물의 설계, 자재, 시공방법의 충실도와 설계여유 등에 따라 영향을 받겠지만 후쿠시마를 비롯한 일 본이나 미국의 앞선 원전 지진피해 사례를 통하여 보더라도 발생지진이 설계지진에 비해 지나치게 크지 않은 한 핵연료 건물의 중대사고 발생 가능성은 극히 낮다고 볼 수 있다. 또 한, 저장조내 표면에 설치되어 있는 스텐레스강 라이너는 하부 콘크리트 구조의 일부 파손 시에는 2 차적인 방수조 역 할을 담당할 것이며, 사용후핵연료 저장조 및 라이너 구조 물 공히 붕괴되어 냉각수 유출이 발생한다면 단시간 내에 저장된 사용후핵연료의 일부 공기중 노출을 방지하기 위한 신속한 대처가 필요하다. 이 때 비상급수 저장탱크나 인근 소방차의 활용으로 일단 사용후핵연료의 공기중 노출방지 및 냉각기능을 최대한 유지시키면서 복구 작업과 함께 사용 후핵연료 수송용기를 활용하여 인근 저장공간으로의 핵연 료 임시 이송이 유리할 수도 있다.(4)

\section{(3) 지진시 저장대 손상}

설계지진보다 큰 지진이 올 경우 저장조 또는 라이너 손 상에 비해 저장대의 손상에 의한 피해는 상대적으로 적을 수 있지만 핵연료의 취급곤란 또는 변형 등에 의해 국부적 인 임계조건을 야기할 수 있으므로 주의가 요구된다. 경수 로형 원전의 경우 지진시 저장대는 일차적으로 각 쎌 내에 서 지지판 위에 자유롭게 놓인 핵연료와 쎌벽과의 좁은 공 간상의 충돌이 예상되고, 저장대 모듈의 저장조 바닥에서의 과도한 슬립 및 기울어짐에 의하여 저장대간 또는 저장조 벽과의 상호충돌이 예상된다.(3) 특히 고밀도 저장대 설계
추세로 저장조내 모듈간 간격이 점차 감소함에 따라 설계지 진 이상의 강진시 모듈간 상호충돌 가능성은 더욱 높아지고 있다. 하지만, 이로 인해 일부 핵연료의 부분 손상이나 저장 대의 일부 변형이 발생하더라도 안전성 측면에서 본다면 수 중에서 냉각 가능상태가 유지되는 한 중대사고의 가능성은 매우 낮다. 중수로형 원전의 경우에도 역시 각 트레이내 오 목한 지지부에 맞춰 놓인 핵연료는 상층에 놓인 트레이가 지지하고 있어서 트레이 내에서는 거동이 제한받을 수 있으 나 수중에 층층이 높게 쌓아 올려 적재된 저장트레이 그룹 의 슬립 또는 기울어짐이 예상되며 강진의 경우 상하 핀삽 입 방식으로 놓여진 특성으로 인하여 일부 무너져 내릴 가 능성을 완전히 배제할 수는 없다. 다만, 중수로형 핵연료의 경우 농축도가 월등히 낮은 핵연료 특성 때문에 일부 구조 적인 피해가 발생더라도 냉각수 환경에서는 임계 가능성이 낮아 중대사고의 우려는 없다고 판단된다.

\section{(4) 저장조내 핵연료 낙하사고}

사용후핵연료 저장대의 핵연료 취급사고는 설계기준 사 고로서 이에 대비한 저장대 구조물의 탄소성 해석을 수행해 오고 있다. 경험적으로 볼 때 핵연료 낙하사고 시 낙하된 핵 연료의 손상, 또는 저장대 상부 쎌구조물 일부의 소성변형 등의 피해를 예측할 수 있지만 해석결과, 그 변형 범위가 일 반적으로 약 쎌 3,4 개 이내의 상부 일부분 크기로서 극히 제한적이다.(5) 또한 저장대는 일반적으로 충분한 설계여유 도를 고려하여 설계되기 때문에 유효 핵연료봉의 최소간격 유지가 가능하며, 이로 인한 핵연료 임계상태 도달 가능성 이 거의 없고, 혹시 발생하더라도 극히 국부적이므로 중대 사고 가능성은 충분히 낮다고 할 수 있다.

\section{(5) 쓰나미에 의한 전원상실 사고}

후쿠시마 사고시와 유사한 쓰나미를 가정할 경우 앞선 설 명에서 비교했듯이 비상발전기 위치가 충분히 높아 소내 전 원상실의 가능성이 낮지만 혹시 전원상실에 의해 냉각기능 상실로 이어지더라도 저장조 내의 냉각수 유출이 없다면 수 위는 자연대류에 의해 며칠간 유지 가능하며 추가로 적정수 위를 유지하도록 비상용수 저장탱크를 활용하거나 소내외 소방차의 지원으로 지속적인 냉각수 보충이 가능하므로 중 대사고는 막을 수 있을 것이다.

\section{(6) 고밀도저장대 교체설치 과정의 가상사고}

국내 사용후핵연료 저장 정책이 국내외적인 환경과도 맞 물려 중간저장 시설의 건설이 지연됨에 따라 최근까지 가급 적 소내저장 용량을 최대화하기 위하여 일부 원전에서 고밀 도 저장대로 교체 작업이 최근까지 이루어지고 있다. 사용 후핵연료 고밀도 저장대 재설치(rerack) 과정도 안전을 고 
려하여 철저한 인허가 과정을 거치고 있지만, 만일 교체 중 에 설계기준 이상의 지진 발생이나 운전사고 상황을 굳이 검토하고자 한다면 첫째, 강진시 남아 있던 저장대 모듈의 비워놓은 공간으로 과도한 기울어짐에 의한 전도가 발생하 는 경우이다. 이때 저장대 내에 보관된 핵연료 일부가 전도 시 충격에 의해 일부 손상될 수도 있지만 저장대 쎌과의 간 극이 좁고 저장대의 영구변형이 크지 않아 핵연료간 최소거 리 유지가 가능하여 임계에 영향을 주지는 않을 것으로 판 단된다. 또한, 저장대 취급중 크레인 운전범위 제한기능 상 실로 인한 저장대 상부로 타 저장대 또는 수송용기의 낙하 충돌사고는 앞선 핵연료 낙하에 비해 변형은 증가하겠지만 일반적으로 사고 발생 확률이 지나치게 낮고 방지하기 위한 서로 독립적인 몇가지 보완책을 동시에 강구하도록 조치함 으로써 이를 예방하고 있다. 심지어 겹겹이 세워진 보완책 을 뜷고 실제로 낙하충돌 사고가 발생한다 하더라도 내진설 계된 냉각계통의 기능 유지가 가능하다면 단계적인 수습에 의해 중대사고는 발생하지 않을 것이다.

\section{IV. 결 론}

본 논문에서는 후쿠시마 원전사고 결과 그 안전중요도가 더 욱 부각된 사용후핵연료 저장시설의 중대사고 관점의 가상사 고 시나리오와 국내 안전성 현황을 검토하였다. 검토 결과 국 내의 경우 원전내 핵연료 임시저장 시설의 안전은 우려할 수 준이 아닌 것으로 나타났지만 우발적인 대형사고 등에 대한 경계심을 항상 늦추면 안 될 것이다. 최근들어 국내를 포함한 원전 주요국들은 정밀점검을 통하여 가동원전들의 안전성을 새로운 시각에서 재평가하여 심층 분석하면서 현재까지의 중 대사고 시나리오 및 설계기준을 크게 강화하는 등 활발한 조 치를 취해오고 있다. 따라서 우리도 일본 사고를 교훈삼아 사 고의 심각성을 정확히 인식하고 주요 시설들의 안전성을 지속 적으로 검토하여 더욱 발전하는 계기로 삼아야 할 것이다.

\section{감사의 글}

본 연구는 한국방사성폐기물관리공단이 시행한 사용후핵 연료 수송/저장시스템 최적화기술 개발사업의 일부로 수행 되었습니다.

\section{참고문헌}

[1] G. C. Song, "Strategy and Roadmap for Spent Fuel
Management", Public Listening for Spent Fuel Management Alternative, (2011.08.19).

[2] T. M. Shin, "Seismic Analysis of Spent Fuel Storage Structures for PHWR Plant”, Fall Conference of KSNVE. pp.338-344 (2003).

[3] T. M. Shin and I. Y. Kim, "Review on the Seismic Analysis Method of Free Standing High Density Fuel Storage Racks of PWR Plants”, Korea Nuclear Society, 27(1) (1997).

[4] T.M. Shin and K.S. Kim, "Study on the Impactproof Internal Structure Design of a Spent Nuclear Fuel Transport Cask", Transactions of the KSNVE, 19(4) (2009).

[5] T.M. Shin, "Analysis of Spent Fuel Storage Racks at Fuel Drop Accident", Fall Conference of KNS (1994). 